\title{
GROWTH FACTOR LOADED FUNCTIONALIZED GOLD NANOPARTICLES AS POTENTIAL TARGETED TREATMENT FOR ACUTE RENAL FAILURE
}

\author{
GAMAL M. ZAYEDa,b, GINA S. EL-FEKY*c \\ aDepartment of Pharmaceutics and Industrial Pharmacy, Faculty of Pharmacy, Al-Azhar University at Assiut, Egypt, bAl-Azhar Centre of \\ Nanosciences and Applications (ACNA), Assiut, Egypt, cDepartment of Pharmaceutical Technology, National Research Center \\ Email: gelfeky@hotmail.com
}

Received: 05 Oct 2018, Revised and Accepted: 19 Nov 2018

ABSTRACT

Objective: Gold nanoparticles (GNPs) have been synthesized and functionalized with chitosan alkanethiol polyethylene glycol as a renal targeting ligand (CS-PEG-AlkSH-GNPs) and finally loaded with insulin-like growth factor-I (IGF-I) for selectively and effectively treating acute renal failure.

Methods: In this study, GNPs were prepared and characterized using transmission electron microscopy, photon correlation spectroscopy and inductively coupled plasma (ICP-OES). The surface of the GNPs was further decorated using synthesized CS-PEG-Alk-SH and IGF-I. IGF-I loaded CSPEG-ALK-SH-GNP were characterized for their growth factor loading capacity, particle size, zeta potential and dispersion stability. In vitro release profile and bioactivity of IGF-I from IGF-I loaded CS-PEG-AlkSH-GNPs were assessed using cell culture technique. Biological distribution, pharmacokinetic investigation and toxicity study of IGF-I loaded CS-PEG-AlkSH-GNPs were carried out using experimental animals.

Results: The size of GNPs was less than $50 \mathrm{~nm}$ with a surface charge of about-45 mV. Coating GNPs with CS-PEG-Alk-SH acquired the particles high in vitro stability in $5 \mathrm{M} \mathrm{NaCl}$ and bovine serum albumin (BSA). The assembly's bioactivity was tested on cell culture and the released IGF-I was found to maintain bioactivity equivalent to its released percentage. When tested on mice, IGF-I loaded CS-PEG-ALK-SH-GNP reached a concentration of $60 \%$ in $6 \mathrm{~h}$ time in the kidneys with an elimination half-life higher than that of the control GNPs indicating efficient renal residence and targeting processes. The system was proved nontoxic.

Conclusion: CS-PEG-AlkSH-GNPs could represent an efficient tool for the targeted delivery of growth factors and other biomolecules to the kidneys.

Keywords: Functionalized gold nanoparticles, Renal targeting, Growth hormone, Cell culture, In vivo study

(C) 2019 The Authors. Published by Innovare Academic Sciences Pvt Ltd. This is an open access article under the CC BY license (http://creativecommons.org/licenses/by/4.0/) DOI: http://dx.doi.org/10.22159/ijap.2019v11i1.30148

\section{INTRODUCTION}

About 200 patients per million develop severe acute renal failure (ARF) yearly $[1,2]$, and might require intensive care unit hospitalization [3]. Dialytic therapy, although life-saving, is expensive, time-consuming and places patients at risk for a diversity of complications [4-7].

In 1984, autocrine and paracrine growth factors were proposed as agents that mediate repair [8, 9-11] in animal models of ARF. Three growth factors including epidermal growth factor (EGF), insulin-like growth factor I (IGF-I) and hepatocyte growth factor (HGF) [12] have been used and their success reported [13, 14], of the three growth factors, IGF-I has shown the highest progress in ARF curing through multiple mechanisms [15-17], and was the first to be used in clinical trials for kidney diseases. Taking into consideration that $\mathrm{ARF}$ is a highly catabolic state; it was observed that unlike EGF or HGF, IGF-I is anabolic even in the setting of acute renal injury.

Recently, GNPs appeared as a type of inorganic metal particles [18, 19] that are extensively studied in therapeutic contexts and in the safe delivery of drugs to a specific site $[20,21]$. Nanoparticles (NPs) have been shown to reach the systemic circulation after inhalation, ingestion or intravenous injection, with further distribution to several organs such as liver, spleen, kidneys, brain or heart [22]. However, their distribution was found to be clearly affected by their particle size [23, 24]. For the biological applications of GNPs in drug targeting, two functional components are required; a stealth layer to increase their circulation time through avoiding their removal by the reticuloendothelial system [25] and a conjugated targeting moiety for targeting a specific receptor and enhancing the mechanism of cellular uptake [26]. Polyethylene glycol (PEG), whose hydrophilic characteristics ensure that the coated particles would have a high degree of biocompatibility, affinity for cell membranes and in turn increased cellular uptake [27]. In addition, it is expected to prevent the aggregation of the GNPs in environments of high ionic strength and supports a longer circulation of the particles was used as the stealth layer, in addition, it was used as a platform to which a renal targeting ligand can be attached [28]. Many authors [29, 30], studied the effect of deacetylation degree of chitosan on renal distribution. The results indicated that low molecular weight chitosan (LMWC) is specifically taken up by renal tubular cells via a megalin-dependent endocytotic pathway and is cleared from the kidneys more rapidly [31-33]. The main aim of the present work was to test the efficacy of IGF-I loaded CS-PEG-ALK-SH-GNP as a possible new selective and effective platform for the treatment of renal failure.

\section{MATERIALS AND METHODS}

\section{Materials}

Tetrachloroauric acid (HAuCl4), polyethylene glycol 4000 (PEG 4000), polyethylene glycol 2000 (PEG 2000), Dichloromethane, Diethyl ether, Tosyl Chloride, Silver Oxide, Toluene, 11Bromoundecene, Thioacetic acid, Sodium azide NaN3, Triphenylphosphine, low molecular weight chitosan, N,N'-Dicyclohexylcarbodiimide (DCC), N-hydroxysuccinimide (NHS), and insulin-like growth factor (IGF) were purchased from Sigma-Aldrich, USA. Other chemicals were of analytical grade

\section{Methods}

Synthesis of amino poly-(ethylene glycol)-undecyl mercaptane $\left(\mathrm{NH}_{2} \mathrm{PEG}_{2000} \mathrm{C}_{11} \mathrm{H}_{22} \mathrm{SH}\right)$ as nanoparticles stabilizing and functionalizing agent

The synthesis of amino poly (ethylene glycol) undecyl mercaptane was carried out in two steps as reported in the literature [34,35]. Briefly, monotosytated PEG 2000 was prepared by reacting dihydroxy poly (ethylene glycol) with toluenesulfonyl chloride in the presence of silver oxide and potassium iodide as shown in fig. 1a. This was followed by the reaction of monoprotected poly (ethylene glycol) with 11 bromroundecene, and the reaction was completed as described in fig. 1b [31]. 


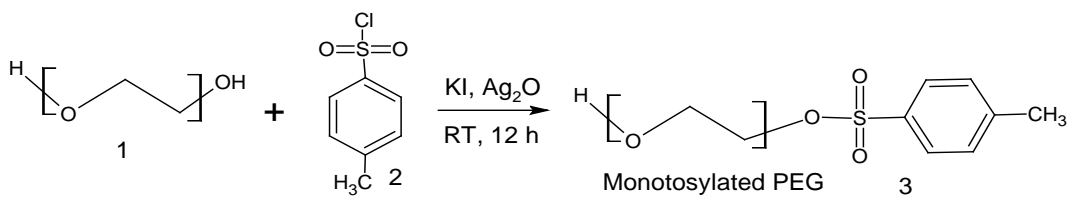

Toluene sulfonyl chloride

(a)
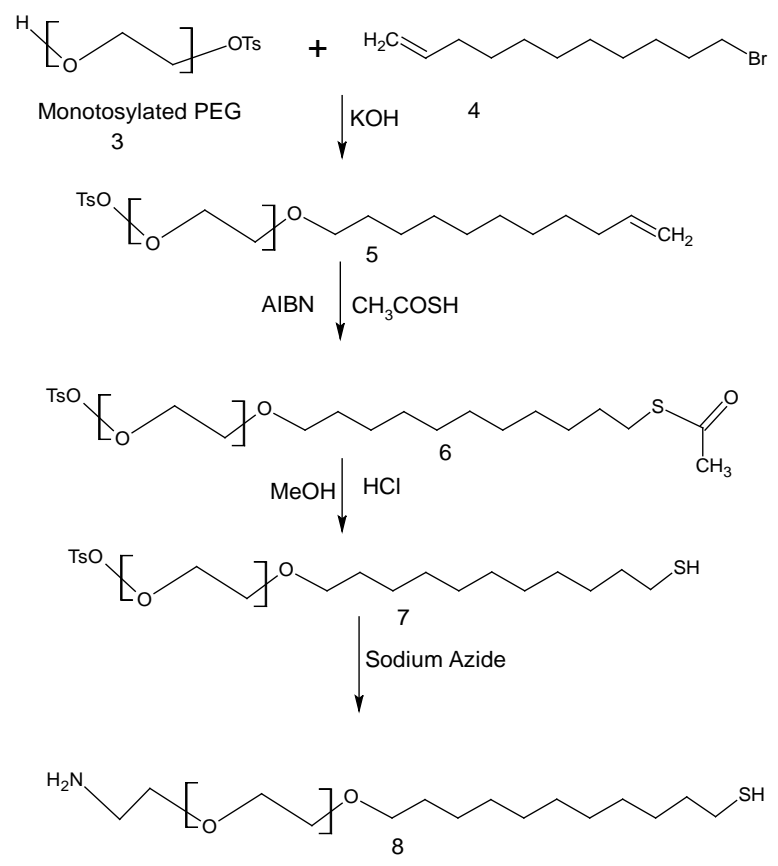

Amino poly(ethylene glycol) mercaptane

(b)

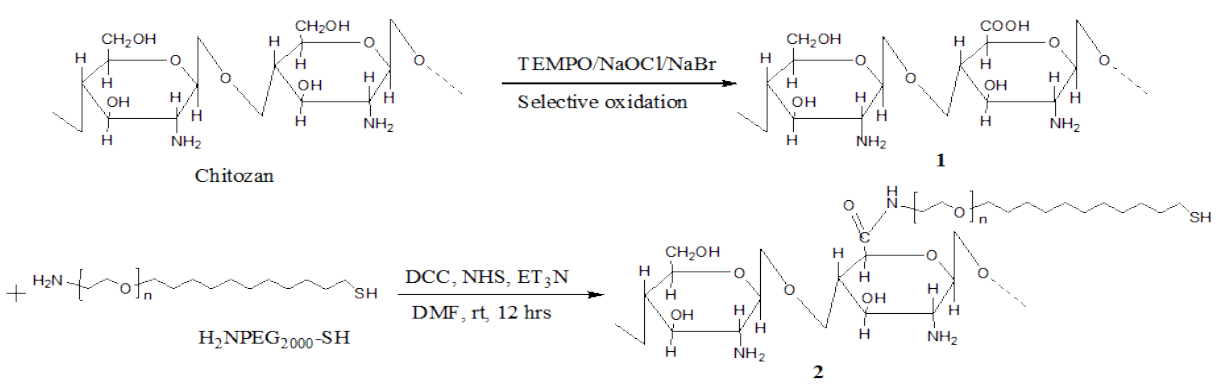

(c)

Fig. 1a: Synthesis of mono-protected poly (ethylene glycol), 1b: Synthesis of amino poly (ethylene glycol) undecyl mercaptane, 1c: Synthesis of low molecular weight chitosan and conjugation to amino polyethylene glycol undecyl mercaptane

\section{Synthesis and characterization of low molecular weight acetylated chitosan renal targeting ligand}

Chitosan-6-carboxylic acid as a new renal targeting ligand has been synthesized by selective oxidation of one $\mathrm{HOCH}_{2}$-group to $\mathrm{COOH}$ according to fig. 1c. The characterization of the prepared renal targeting ligand was carried out using ${ }^{1} \mathrm{H}-\mathrm{NMR}$ spectroscopy and FTIR $[36,37]$.

Conjugation of the synthesized polymer with the renal targeting ligand (chitosan)

Amino polyethylene glycol undecyl mercaptane $\left(\mathrm{NH}_{2}\right.$ - PEG-AlkSH) polymer was conjugated with the low molecular weight chitosan through reacting the amine group $\left(\mathrm{NH}_{2}\right)$ of the amino polyethylene glycol undecyl mercaptane with the carboxyl group $(\mathrm{COOH})$ of the prepared renal targeting ligand; chitozan-6-carboxylic acid; according to fig. $1 \mathrm{c}$.

Chitosan conjugated polyethylene glycolalkanethiol CS-PEG-AlkSH (fig. 1c, compound 2) was prepared by dissolving Chitosan (0.5 mmol) in dry dimethylformamide DMF (15 ml) then triethylamine $(2.5 \mathrm{ml})$, NHS (115 mg, $1 \mathrm{mmol})$ and DCC (124 mg, $1.2 \mathrm{mmol})$ were added and the reaction mixture was stirred at room temperature for $12 \mathrm{~h}$. This step aimed at activating the carboxyl group of chitosan. After that, $\mathrm{NH}_{2}$-PEG-AlkSH (1.0 gm, $0.5 \mathrm{mmol}$ ) was added and the whole reaction mixture was stirred overnight at room temperature. 
At the end of the reaction, filtration was carried out (to remove dicyclohexylurea), and DMF was evaporated under vacuum till dryness. The crude product was dissolved in methylene chloride and precipitated by dropwise addition to an ice cooled ether. The desired product was collected by filtration. The produced compound (polymer conjugated chitosan) was characterized by FT-IR and ${ }^{1} \mathrm{H}-$ NMR [36, 38].

\section{Characterization of the synthesized polymer}

The synthesized polymers were characterized by ${ }^{1} \mathrm{H}-\mathrm{NMR},{ }^{13} \mathrm{C}-\mathrm{NMR}$. For NMR of the polymer, they were dissolved in $\mathrm{CDCl}_{3}$ with tetramethyl silane as internal standard and subsequently measured using Bruker Avance 400 spectrometer (Bruker Biospin, Rheinstetten, Germany).

\section{Preparing gold nanoparticles by the citrate reduction method}

Gold nanoparticles were obtained by the reduction of $\mathrm{HAuCl}_{4}$ in an aqueous medium using trisodium citrate as a reducing agent. Special precautions were taken to avoid uncontrolled growth and aggregation of nanoparticles during preparation. The used weight per weight ratios of gold salt to citrate salt were 1:10, 1:20 and 1:30 [39].

In this method, the citrate salt acts initially as the reducing agent to reduce $\mathrm{Au}$ (III) $3+$ ions to $\mathrm{Au}(0)$ and later also functions as stabilizing agent by forming a layer of citrate anions on top of the nanoparticles' surface, thus, charging the particles by negative charges and inducing enough electrostatic repulsion forces between individual particles to keep them uniformly dispersed in the synthesis medium [40]

\section{Characterization of the prepared nanoparticles}

\section{UV-Vis scanning of gold nanoparticles}

Ultraviolet-visible light absorption spectra of citrate-stabilized, and polymers coated gold nanoparticles were taken at room temperature using a double beam spectrophotometer (Shimadzu 1601, Japan). Two ml solution of gold nanoparticles was placed in a quartz cuvette, and the spectrum of the solution was recorded [41].

\section{Size and surface charge measurements by photon correlation spectroscopy (PCS)}

The size, size distributions and the zeta potentials of the synthesized gold nanoparticles were analyzed by PCS using a Zeta sizer ZS 90 (Malvern, Instruments GmbH, England). $300 \mu \mathrm{l}$ of GNPs were added to $3 \mathrm{ml}$ of Millipore water immediately before measuring their size and zeta potential. The refractive index and the viscosity of dispersion medium (water) were used for the calculation of the results [42].

\section{Imaging of gold nanoparticles by Transmission Electron Microscopy (TEM)}

Ten $\mu \mathrm{l}$ of the nanoparticle samples will be dropped on graphite coated copper grids and dried at room temperature before taking the images by TEM (Zeiss EM 10 C/CR, Germany) [34].

\section{Dispersion stability of nanoparticles}

To simulate the in vivo conditions, the dispersion stability of bare and coated GNPs in high ionic strength solutions ( $5 \mathrm{M} \mathrm{NaCl})$, bovine serum albumin (BSA, $200 \mu \mathrm{g} / \mathrm{ml})$ and plasma (10\% v/v) were applied using UV-Vis absorption spectroscopy [41].

\section{Determination of nanoparticles concentration}

The concentration of GNPs in the prepared solution was calculated using inductively coupled plasma (ICP-OES) (Horiba Jobin Yvon, $70 \mathrm{P}, \mathrm{S}+\mathrm{S}$, Munich, Germany). Firstly, $1 \mathrm{ml}$ of GNPs solution was digested to gold salt $\left(\mathrm{Au}^{+3}\right)$ by mixing with $2 \mathrm{ml}$ of aqua regia $(\mathrm{HCl}$ : HNO3, 3:1 volume ratio). Complete dissolution of GNPs was observed within half an hour after the addition of aqua regia to colloidal gold. The amount of gold salt in digested solution was analyzed by ICP-OES at emission wavelengths of 268 and $243 \mathrm{~nm}$. The concentration was calculated based on the standard curve constructed by using different concentrations of auric chloride. The concentration was calculated based on a standard curve constructed by using different concentrations of auric chloride $[34,43]$.

\section{Preparation and characterization of the functionalized GNPs} loaded with the growth factor

\section{Decorating the surface of GNPs with $\mathrm{NH}_{2}$-PEG-AlkSH and CS- PEG-AlkSH}

Excess amounts of either $\mathrm{NH}_{2}$-PEG-SH or CS-PEG-AlkSH were added to GNP solution $(5 \mu \mathrm{g} / \mathrm{ml})$ to ensure complete coating of the particles' surface with polymers. The resulting mixture was shacked overnight in a horizontal shaker set to $200 \mathrm{rpm}$ at room temperature to allow the exchange of citrate anions with the thiol group of the polymers on the particle's surface. The excess unbound polymer was removed by four times ultra-filtration at $750 \mathrm{~g}$ [34].

\section{Preparation of IGF-I loaded CS-PEG-AlkSH-GNPs}

The positive charge of GNPs coated with chitosan can adsorb the negatively charged growth factors, such as IGF-I, by electrostatic attraction. Growth factors were loaded to CS-PEG-AlkSH-GNPs in a concentration of $100 \mathrm{ng} / \mathrm{ml}$. An excess amount of IGF-I was added to the nanoparticles, and the free unbound drug was removed by ultrafiltration.

\section{Determination of loading efficiency}

The loading efficiency (\%) of IGF-I loaded CS-PEG-AlkSH-GNPs was carried by determining the difference in concentrations between the added IGF-I (100 ng/ml) and the concentration determined in the supernatant. Two $\mathrm{ml}$ of nanoparticles containing IGF-I were filtrated $(14,000 \mathrm{~g}, 30 \mathrm{~min})$ and the IGF-I concentration in the filtrate was determined by using IGF-I ELISA (enzyme-linked immunoassays) kits (eBioscience, San Diego, CA, US) according to the manufacturer's instructions. This experiment was repeated three times, and encapsulation efficiency (EE) was calculated by applying the following equation $[44,45]$ :

$$
\begin{aligned}
\mathrm{LE}=[\text { (Concentration of the added IGF } & \\
& \quad-\text { Concentration of IGF in the supernatant }) \\
& \quad-(\text { Concentration of the added IGF })] * 100
\end{aligned}
$$

\section{Characterization of IGF-I loaded CS-PEG-AlkSH-GNPs}

Nanoparticles loaded with IGF-I were characterized using UV-visible spectroscopy, particle size analysis, zeta potential measurements and the dispersion stability as mentioned earlier.

\section{In vitro release, profile and bioactivity of IGF-I from IGF-I loaded CS-PEG-AlkSH-GNPs using cell culture technique}

The in vitro release profile of IGF-I from CS-PEG-AlkSH-GNPs was determined using eppendorf tubes, each filled with $250 \mu \mathrm{l}$ PBS buffer of $\mathrm{pH} 7.4$, containing $1 \% \mathrm{w} / \mathrm{v}$ BSA. Three mg of IGF-I loaded CS-PEGAlkSH-GNPs were added to each eppendorf tube. The tubes were closed and incubated in a shaking water bath $(100 \mathrm{rpm})$ at $37^{\circ} \mathrm{C}$. At different time intervals, a specific number of eppendorf tubes were collected and centrifuged for $5 \mathrm{~min}$ at 3,000 rpm, and the supernatants were collected for IGF-I determination using ELISA ( $R$ and D systems, France). The cumulative release percentage was calculated based on the total amount of IGF-I obtained from the loading efficiency experiment.

The IGF-I released at different time intervals from CS-PEG-AlkSHGNPs were checked for their bioactivity using cell culture technique. Human breast carcinoma (MCF-7) cell line was obtained from the American Type Culture Collection (ATCC, Rockville, MD). The cells were grown on RPMI-1640 medium supplemented with $10 \%$ inactivated fetal calf serum and $50 \mu \mathrm{g} / \mathrm{ml}$ gentamycin. The cells were maintained at $37{ }^{\circ} \mathrm{C}$ in a humidified atmosphere with $5 \% \mathrm{CO}_{2}$ and were sub-cultured two to three times a week.

For cell count assays, the cell lines were suspended in the medium at concentration $5 \times 10^{4}$ cell/well in Corning ${ }^{\circledR}$ 96-well tissue culture plates and then incubated for $24 \mathrm{~h}$. Two compounds were tested; free IGF-I and IGF-I loaded CS-PEG-AlkSH-GNP. Each of the two compounds was added into 96-well plates (six replicates) to achieve eight concentrations for each compound. After incubating for two days, the numbers of viable cells were determined by the MTT test. 
Briefly, the media was removed from the 96 well plates and replaced with $100 \mu$ l of fresh culture RPMI-1640 medium without phenol red then $10 \mu \mathrm{l}$ of the $12 \mathrm{mmol}$ MTT stock solution $(5 \mathrm{mg}$ of MTT in $1 \mathrm{ml}$ of PBS) to each well including the untreated controls. The 96 well plates were then incubated at $37{ }^{\circ} \mathrm{C}$ and $5 \% \mathrm{CO}_{2}$ for $4 \mathrm{~h}$. An $85 \mu \mathrm{l}$ aliquot of the media was removed from the wells, and $50 \mu$ of DMSO was added to each well and mixed thoroughly with the pipette and incubated at $37{ }^{\circ} \mathrm{C}$ for $10 \mathrm{~min}$. Then, the optical density was measured at $590 \mathrm{~nm}$ with the microplate reader (SunRise, TECAN, Inc, USA) to determine the number of viable cells and the percentage of viability was calculated as [1-(ODt/ODc)] $100 \%$ where ODt is the mean optical density of wells treated with the tested sample and ODc is the mean optical density of untreated cells [46].

\section{In vivo study}

For the in vivo investigation two types of functionalized GNPs were prepared, IGF-I loaded CS-PEG-ALK-SH-GNP (see section 2.7.1) and $\mathrm{CH}_{3} \mathrm{O}$-PEG-ALK-SH-GNP, the latter was prepared as per the scheme reported by Zayed and Tessmar in 2012 and by Khaled et al., in 2016 $[34,41]$. $\mathrm{CH}_{3} \mathrm{O}$-PEG-ALK-SH-GNP was used as a positive control functionalized GNPs to evaluate the true targeting power of CS ligand in vivo.

\section{Animal Bio-distribution of control $\left(\mathrm{CH}_{3} \mathrm{O}\right.$-PEG-ALK-SH-GNP) and targeted}

\section{(CS-PEG-ALK-SH-GNP) gold nanoparticles}

The in vivo biodistribution experiments were carried out using male mice weighing between 50 and $60 \mathrm{~g}$ (provided by the animal house of Assiut University, Egypt). Animal ethical approval was obtained from Ethics Committee of the Faculty of Pharmacy, Al-Azhar University, Assiut (approval code pharmaceut02) and was carried out in accordance with the National Institutes of Health guide for the care and use of Laboratory animals (NIH Publications No. 8023, revised 1978)

Three groups of animals were used; Group 1: negative control group and it was used for the toxicity study, Group 2: injected with $200 \mu \mathrm{l}$ of the dispersions of the control CH3O-PEG-ALK-SH-GNP and Group 3: injected with $200 \mu \mathrm{l}$ of the dispersions of the IGF-I loaded CS-PEG-ALK-SH-GNP. Group 2 and 3 were injected intravenously in the tail vein of each anesthetized mouse. The animals had free access to food and water ad libitum before and during the experiments. At specific time intervals of $15 \mathrm{~min}, 1,6$ and $24 \mathrm{~h}$ after the injection of GNPs, four injected mice were sacrificed, and blood samples were withdrawn in heparin zed tubes, and the main organs of each mouse including liver, spleen, and kidneys were collected. Blood samples were stored at $6{ }^{\circ} \mathrm{C}$ while the organs were stored at $-80^{\circ} \mathrm{C}$ till further analysis.

\section{Digestion of collected organs}

Each of the collected organs was accurately weighed, homogenized and digested by aqua regia (concentrated $\mathrm{HCl}$ and concentrated $\left.\mathrm{HNO}_{3} ;(3: 1 \mathrm{v} / \mathrm{v})\right)$ for the determination of their gold content using inductively coupled plasma optical emission spectroscopy (ICPOES). The concentration of gold in each of the assessed tissues was calculated and expressed as percent of the initially injected dose per gram (\% ID/g) [47].

\section{Pharmacokinetic investigation of control and targeting GNPs}

The pharmacokinetic profile of both $\mathrm{CH}_{3} \mathrm{O}$-PEG-ALK-SH-GNP and IGF-I loaded CS-PEG-ALK-SH-GNP was determined in two groups of experimental mice at $0.25,0.5,0.75,1,2,6,8,15,18$ and 24 h post injection. The concentrations of gold in blood samples was calculated and expressed as percent of the initially injected dose per gram (\% ID/g). The pharmacokinetic profiles covered the concentration at zero time $\left(\mathrm{C}_{0}\right)$, the elimination rate constant $(\mathrm{Ke})$, the half-life $\left(t_{0.5}\right)$, the volume of distribution $\left(\mathrm{V}_{\mathrm{d}}\right)$ and the clearance (Cl) of both systems. Analysis was done using WinNonlin software (Version 2.1; Pharsight, Mountain View, CA).

\section{Toxicity study}

\section{Macroscopic examination}

Tissues of organs isolated from the three groups of mice were investigated comparatively for changes in size, color, and morphology. Mice were also monitored for behavioral changes.

\section{Haematology analysis}

The blood of negative control mice as well as after intravenous injection of both $\mathrm{CH}_{3} \mathrm{O}-\mathrm{PEG}-\mathrm{ALK}-\mathrm{SH}-\mathrm{GNP}$ and IGF-I loaded CS-PEGALK-SH-GNP was collected at 1, 6 and 18 and $24 \mathrm{~h}$ in heparin tubes for haematology indexes analysis. These included haemoglobin ( $\mathrm{Hb})$, total white (WBC) and red (RBC) blood cell counts, lymphocytes (Lph), monocytes (Mono), and granulocytes (GR) counts.

\section{Clinical chemistry analysis}

The blood of negative control mice as well as after intravenous injection of both $\mathrm{CH}_{3} \mathrm{O}$-PEG-ALK-SH-GNP and IGF-I loaded CS-PEGALK-SH-GNP was collected at 1, 6 and 18 and $24 \mathrm{~h}$, then it was centrifuged at $5000 \mathrm{rpm}$ for $10 \mathrm{~min}$ to separate the serum for analysis. Serum clinical chemistry indexes analyzed included creatine (CR), aspartate aminotransferase (AST), alanine aminotransferase (ALT) and albumin (ALB).

\section{Statistical analysis}

Results are expressed as mean $\pm \mathrm{SD}$ or mean $\pm \mathrm{SE}$ of multiple independent experiments. One-way analysis of variance (ANOVA) test was used to compare results between groups. Significance was set at ${ }^{*} \mathrm{p}<0.05$, and statistical analysis was performed using MINITAB (Version 16.0; Minitab, State College, Pennsylvania, USA) and SPSS (Version 17.0; SPSS, Cary, North Carolina, USA).

\section{RESULTS AND DISCUSSION}

Synthesis of amino poly (ethylene glycol)-undecyl mercaptane $\left(\mathrm{NH}_{2} \mathrm{PEG}_{2000} \mathrm{C}_{11} \mathrm{H}_{22} \mathrm{SH}\right)$

Alkanethiol PEG amine was synthesized according to the methods previously reported by Zayed and Tessmar, 2012 [34], Khaled et al., 2016 [41] and Mohamed et al., 2016 [48] through the selective tosylation of one terminal hydroxyl group of PEG 2000 diol to produce mono-protected PEG (intermediate 3, fig. 1). The results of the ${ }^{1} \mathrm{H}$-NMR spectrum of this compound showed the following signals; [13]C-NMR $\left(\mathrm{CDCl}_{3}\right) \delta: 145,133.24,130.04,128.21,72.19$, $70.79,69.39,61.95,21.87,\left(\mathrm{CDCl}_{3}, \delta\right.$ in ppm): $7.79(2 \mathrm{H}, \mathrm{d}, \mathrm{J}=8 \mathrm{~Hz})$, $7.49(2 \mathrm{H}, \mathrm{d}, \mathrm{J}=8 \mathrm{~Hz}), 4.56(1 \mathrm{H}, \mathrm{t}, \mathrm{J}=5.4 \mathrm{~Hz}, \mathrm{OH}), 4.11(2 \mathrm{H}, \mathrm{t}, \mathrm{J}=4.4$ $\left.\mathrm{Hz}, \mathrm{CH}_{2}-\mathrm{SO}_{2}\right), 3.49$ (128H, s, PEG backbone), $2.43\left(3 \mathrm{H}, \mathrm{s}, \mathrm{CH}_{3}\right)$. The spectrum of the final product (fig. 2) obtained after the treatment of intermediate (6) by $\mathrm{HCl}$ and sodium azide showed the following signals; (CDCl3) 3.5-3.9 (m, 180H, $\left.\mathrm{OCH}_{2} \mathrm{CH}_{2}\right), 3.45\left(\mathrm{~m}, 2 \mathrm{H},-\mathrm{OCH}_{2}-\right)$, $2.8\left(\mathrm{t}, \mathrm{t}, 2 \mathrm{H},-\mathrm{CH}_{2} \mathrm{NH}_{2}\right), 2.55\left(\mathrm{tt}, 2 \mathrm{H},-\mathrm{CH}_{2} \mathrm{SH}\right)$ and $1.7-1.2(\mathrm{~m}, 18 \mathrm{H}$, the remaining protons of the alkanepart).

Synthesis and characterization of renal targeting ligand and conjugation with amine PEG-thiol

The conversion of chitosan's secondary hydroxyl groups into a carboxylic acid functional group was confirmed using FT-IR where the characteristic carbonyl $(\mathrm{C}=0)$ band appeared at $1742 \mathrm{~cm}^{-1}[37]$. FT-IR of chitosan conjugated polyethylene glycol was characterized by the bands at 3470, 3295, $1734 \mathrm{~cm}^{-1} .{ }^{1} \mathrm{H}-\mathrm{NMR}$ (DMSO-d6) 11.58 (s, $1 \mathrm{H}, \mathrm{CONH}) ; 4.75(\mathrm{~m}, 1 \mathrm{H}, \mathrm{CHCONH}), 4,25\left(\mathrm{~m}, 2 \mathrm{H}, \mathrm{CH}-\mathrm{CH}_{2} \mathrm{O}\right), 3.2-3.7$ $(190 \mathrm{H}, \mathrm{m}, \mathrm{PEG}$ backbone and remaining protons of chitosan), 2.85 (m, $\left.2 \mathrm{H}, \mathrm{CH}-\mathrm{NH}_{2}\right), 2,54\left(\mathrm{~m}, 2 \mathrm{H}, \mathrm{CH}_{2} \mathrm{SH}\right), 2.25(\mathrm{~m}, 1 \mathrm{H}, \mathrm{CH}-\mathrm{CHCONH})$, $1.10-1.70(\mathrm{~m}, 20 \mathrm{H}$, proton of alkyl skeleton).

\section{Preparing GNPs by citrate reduction method}

The addition of sodium citrate solution caused a gradual change in the color of the boiling auric chloride solution from pale yellow to deep red. The complete development of the deep red color was obtained after boiling the solution for 20 min. Obtained GNPs are recorded to be monodisperse spheres the size of which is determined by the concentration of the used citrate anions and the chosen reaction conditions.

\section{Characterization of the prepared nanoparticles}

\section{UV-Vis scanning of GNPs}

The spectrum of prepared GNPs is characterized by strong absorbance in the visible region at about $520 \mathrm{~nm}$ due to surface 
plasmon resonance. The aqueous dispersions of GNPs showed a surface plasmon resonance at $524 \mathrm{~nm}$, which originates form oscillation of the surface electron of the particles upon exposure to light and agrees with the findings of Zayed and Tessmar [34]. The $\lambda$ max of the spectrum does not differentiate between the different sizes of the particles, it only provides a rough estimation of the particles size range [34].

\section{Size and surface charge measurements by PCS}

The hydrodynamic sizes and surface charges of the obtained GNPs are listed in table 1 and the size distribution is graphically presented in fig. 3.

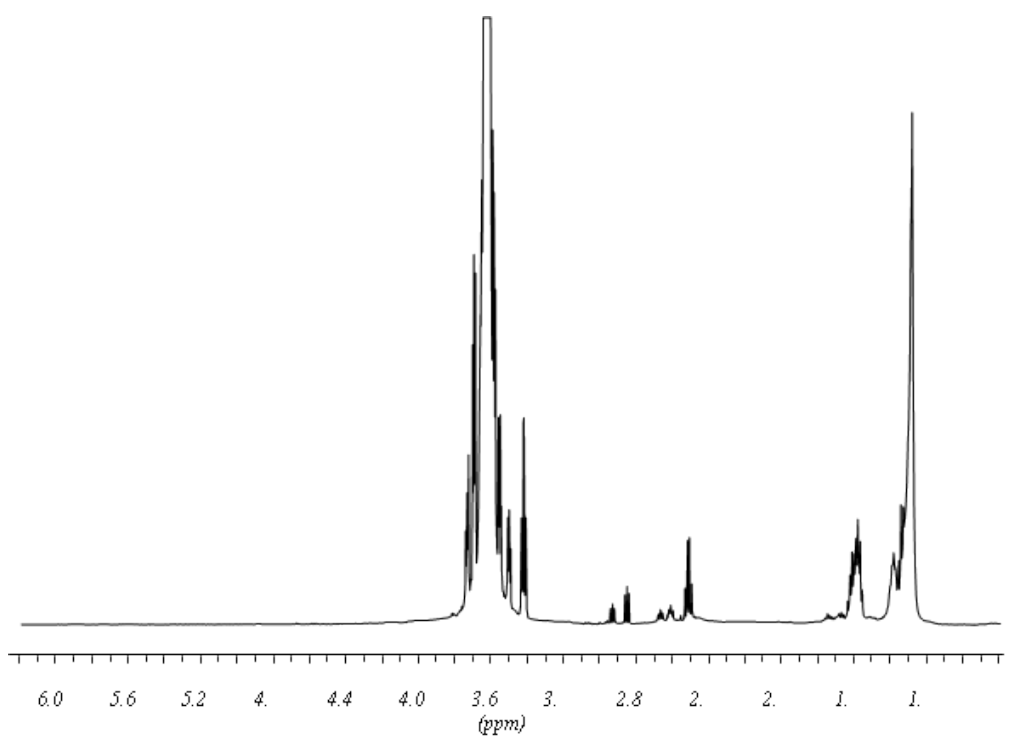

Fig. 2: ${ }^{1} \mathrm{H}-\mathrm{NMR}$ spectrum of amino poly (ethylene glycol) undecyl mercaptane $\left(\mathrm{NH}_{2}-\mathrm{PEG}_{2000} \mathrm{C}_{11} \mathrm{H}_{22} \mathrm{SH}_{\text {) }}\right.$

Table 1: The size, PI and surface charges of naked and coated GNPs

\begin{tabular}{llll}
\hline Gold/Citrate ratio & Size* $^{*}(\mathbf{n m})$ & Polydispersity index (PI) & Surface charges \\
\hline $1: 10$ & $47.6 \pm 1.82$ & 0.384 & -47.12 \\
$1: 20$ & $27.8 \pm 1.34$ & 0.5 & -42.19 \\
$1: 30$ & $22.5 \pm 0.65$ & 0.416 & -39.13 \\
Citrate stabilized GNPs $(1: 30)$ & Size* $(\mathrm{nm})$ & Poly dispersity index (PI) & Surface Charges \\
GNPs coated with NH2-PEG-AlkSH & $27.8 \pm 2.45$ & 0.430 & -3.19 \\
GNPs coated with CS-PEG-AlkSH & $28.5 \pm 1.93$ & 0.425 & 5.5 \\
\hline
\end{tabular}

*(Results are expressed as mean $\pm \mathrm{SD}, \mathrm{n}=3$ )

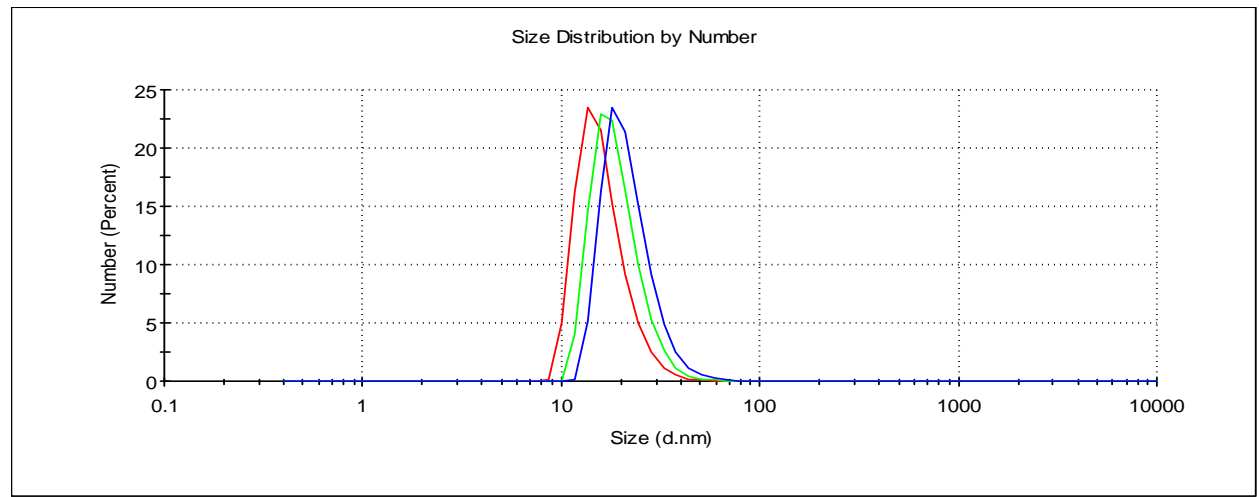

Fig. 3: PCS showing the size distribution of different GNPs batches

As shown from size determination (table 1), an inverse proportion between the concentration of reducing agent (sodium citrate) and the size of the produced particles was detected, i.e., as the concentration of sodium citrate increases, the size of GNPs decreases. This finding could be explained on the bases that a higher citrate/gold ratio produces more nuclei of $\mathrm{AU}{ }^{\circ}$ and hence, a large proportion of auric salts is consumed in the formation of nuclei and in turn, will not be available for the excessive deposition on the surface of the formed nuclei instead, it will be distributed over a relatively larger number of nuclei leading to the formation of small GNPs. Also, when the amount of sodium citrate decreases, inadequate amount of citrate anions is available to fully cover the formed GNPs resulting on thermostatically unstable GNPs which will aggregate together to form larger particles [49].

All the prepared batches showed a polydispersity index (PI) less than 0.7 which indicates that the size variation between the individual particles is very small and mostly monodisperse 
nanoparticles are formed. The negative surface charge of the prepared particles is attributed to the adsorption of citrate anions on the particles' surfaces $[40,48]$.

\section{Imaging of GNPs by TEM}

The TEM image of GNPs obtained by using 1:30 gold/citrate ratio is shown in fig. 4. GNPs showed mostly a spherical shape while few were polygonal. The size determined by TEM was found to be slightly smaller than the size determined by PCS. This observation might be due to that TEM determines the dense electron mass of the particles while PCS determines the hydrodynamic size of the particles i.e., the size of GNPs together with the moving adjoining layer of the water, adsorbed anions and/or coating polymers [34].

\section{Dispersion stability of nanoparticles}

The effects of sodium chloride, BSA and plasma on the stability of the prepared nanoparticles are shown in fig. 5. High concentration of sodium chloride $(5 \mathrm{M})$ induced rapid aggregation of GNPs as indicated by the change of color from wine red to blue and the disappearance of UV-Vis characteristic absorption peaks. This effect is due to the neutralization of surface charges of the particles which is considered the main reason for the dispersion stability. Neutralization of the surface charges might have resulted in reduced electrostatic repulsion between individual particles and consequently, the hydrophobic-hydrophobic interaction was expected to be the prominent force acting on nanoparticles. These conditions lead to aggregation of nanoparticles, size increase, change of color form wine red to blue and finally the disappearance of the UV-Vis characteristic absorption peaks. Similar effects were observed when aqueous citrate-coated GNPs solutions were mixed with BSA and plasma which could also be due to the masking of the negative charges present on the particle surface, similar results were recorded by Mohamed et al., and Shalkevich et al. [48, 51].

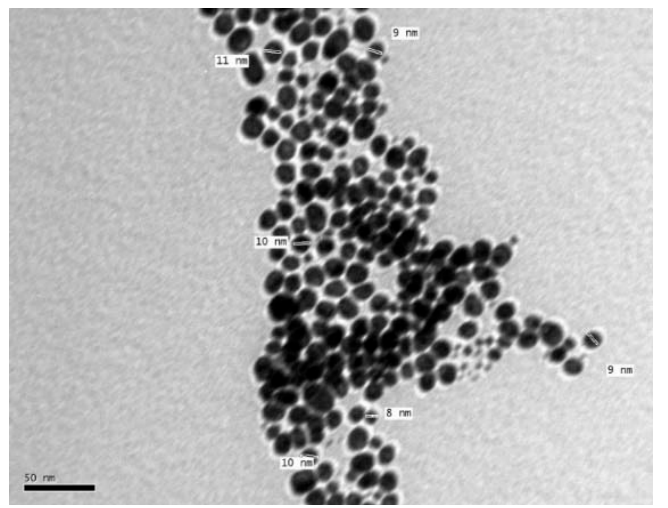

Fig. 4: TEM image of GNPs obtained by using 1:30 gold to citrate ratio

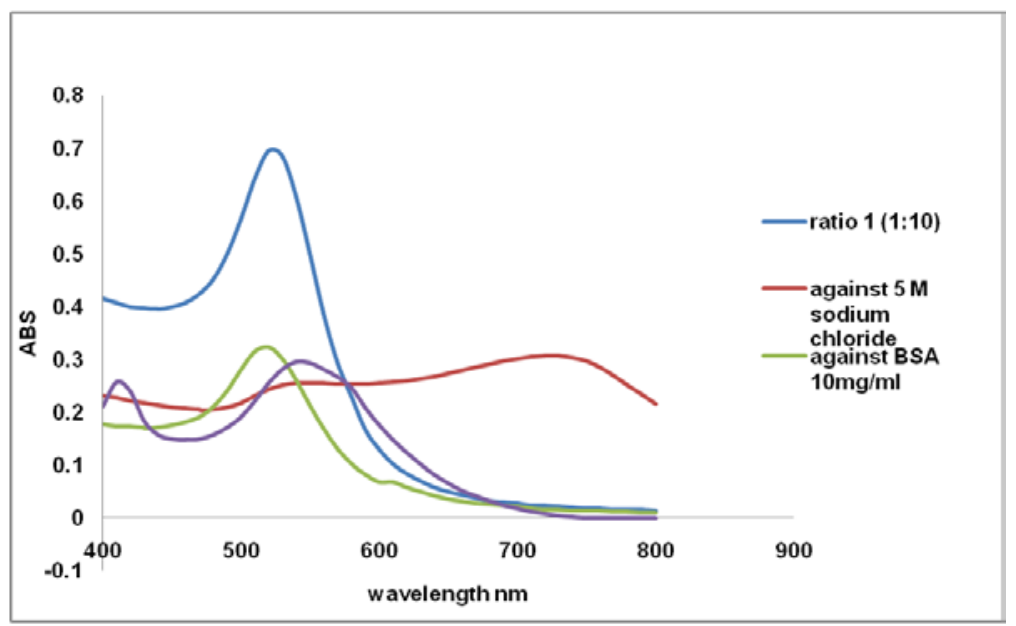

Fig. 5: Effect of sodium chloride, plasma, and BSA on the UV-Vis spectroscopy of citrate-stabilized GNPs

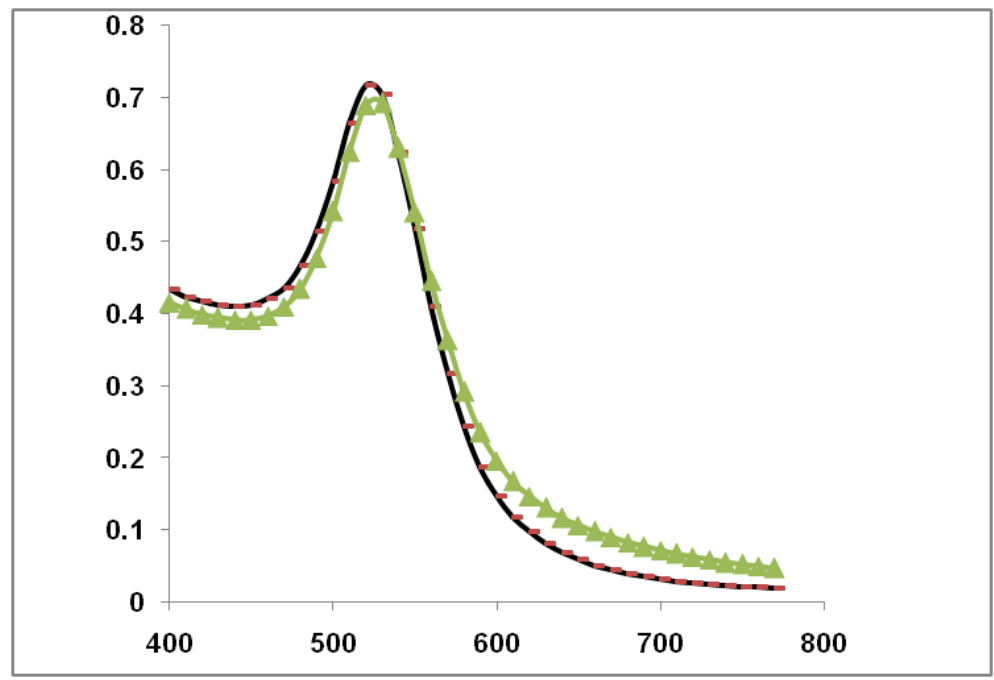

Fig. 6: UV-Vis absorption spectra of citrate-stabilized (black line) and coated GNPs (green color) 


\section{Determination of nanoparticles concentration}

The concentration of gold in the different batches of the prepared GNPs was determined using ICP-OES. Results indicate that almost all of the added gold salt has been converted to GNPs which means that the reduction of auric chloride is about $100 \%$ completed by the sodium citrate method [51,52].

\section{Preparation, characterization and loading efficiency of the} functionalized GNPs loaded with the IGF-I

Monodisperse red colored GNPs obtained by the citrate reduction of auric chloride solution were characterized by strong absorbance in the visible region of UV-Visible spectrum at about $520 \mathrm{~nm}$ due to the surface plasmon resonance after exposure to light as mentioned earlier, while, the polymer modified nanoparticles with synthesized polymers were characterized by surface plasmon resonance at 527 $\mathrm{nm}$ as shown in fig. 6 .

The size, zeta potential, and polydispersity index (PI) of citratestabilized and polymer-coated GNPs are shown in table 1 . The size of citrate-stabilized GNPs was about $22 \mathrm{~nm}$. While coating the nanoparticles with polymer resulted in an increase in the size by about $5 \mathrm{~nm}$. This was previously reported by Sebak in 2018 where the author reported particle size enlargement comparing of

\section{PEGylated to non-PEGylated nanoparticles [50]}

The increase in size might be due to the attachment of the polymer molecules on the particles' surfaces. All the prepared GNPs showed polydispersity indices less than 0.5 which indicate the narrow size distribution of the particles. The surface charge (zeta potential) of citrate-stabilized GNPs was found to be about- $40 \mathrm{mV}$ which might have resulted from the adsorption of citrate anions on the surfaces of the nanoparticles. Coating GNPs with amine terminated PEG lead to a decrease in the negative surface charge from $-40 \mathrm{mV}$ to about- 3 $\mathrm{mV}$. Additionally, coating the GNPs with CS-PEG-AlkSH resulted in a shift of the surface charge form about $-40 \mathrm{mV}$ to about $5 \mathrm{mV}$. The change of zeta potential after coating with $\mathrm{NH}_{2}$-PEG-SH polymer and chitosan modified polymer might be due to the attachment of the polymer amine groups which were mostly protonated and became positively charged with the negative charges resulting from the citrate anions thus, causing a neutralization state. Attachment of the polymer to gold surface led to the replacement of some of the adsorbed citrate anions form the nanoparticles' surface. This finding could be considered a strong evidence of the efficient coating of GNPs with the polymer [34].

The loading efficiency of IGF-I on the surface of functionalized GNPs was found to be $61.5 \pm 2.37 \%$.

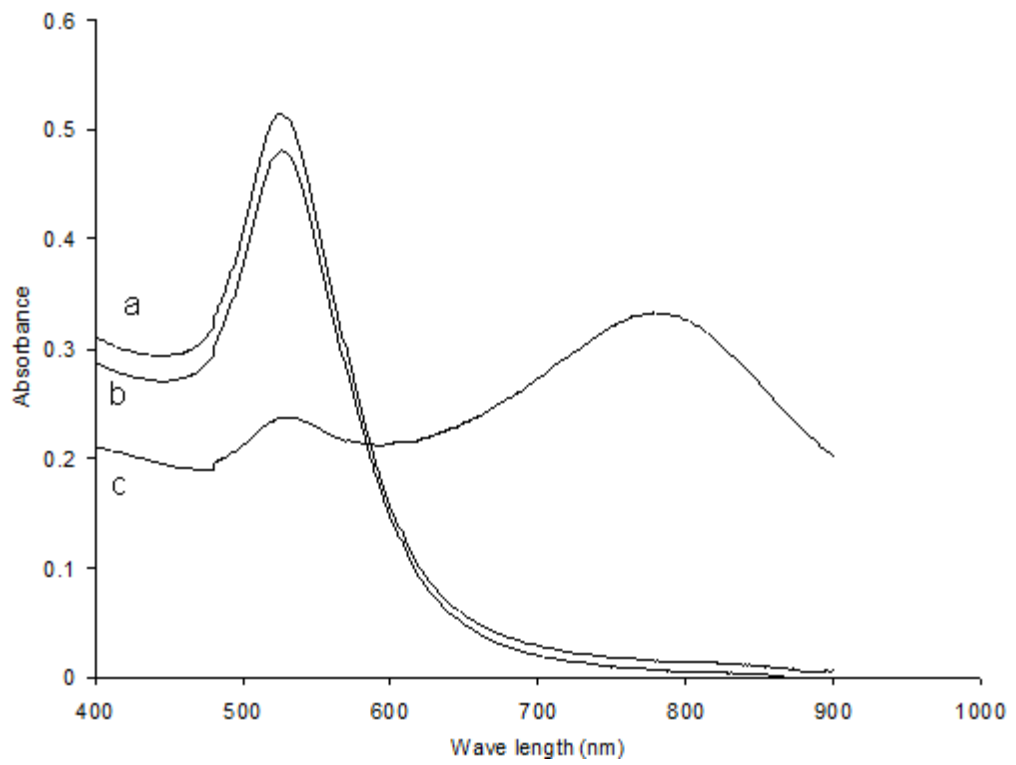

Fig. 7: Effect of sodium chloride on the UV-Vis absorption spectra of, $\mathrm{NH}_{2}$-PEG-AlkSH coated GNPs (a), CS-PEG-AlkSH coated GNPs (b) and citrate stabilized (c)

\section{Effect of coating GNPs with polymer on the stability in biological media}

Citrate-stabilized GNPs are unstable in the presence of electrolyte and proteins as indicated by the large increase in its size and the disappearance of the characteristic surface plasmon resonance as shown in fig. 5 and 7. The instability of citrate-coated GNPs in the presence of electrolytes and protein could be attributed to the masking and the neutralization of the surface negative charges which were the main reason of the stability of citrate-stabilized GNPs. The polymeric coated GNPs were found not to be affected by the presence of electrolyte and proteins. This finding might be due to the stabilization of the polymeric coated nanoparticles sterically rather than by electrostatic repulsion. Sterically stabilized GNPs were reported to be the most suitable form of GNPs for biological application [34].

In vitro release profile of IGF-I from IGF-I loaded GNPs and released IGF-I bioactivity assessment using cell culture

IGF-I release profile from functionalized GNPs was quantified in vitro by ELISA and showed a $58.2 \%$ IGF-I release after $24 \mathrm{~h}$ (fig. 8).
Human breast carcinoma (MCF-7) cell line was selected to assess the bioactivity of IGF-I loaded CS-PEG-AlkSH-GNPs because this type of cell line expresses much higher levels of insulin receptor substrate than other cell lines, and consequently, it is expected to be extremely sensitive to any change on the IGF-I concentrations giving more accurate and more measurable results $[52,53]$. Cell culture results showed that there was no difference in cell count between the free IGF-I and IGF-I loaded CS-PEG-ALK-SH-GNP compounds. These results indicate that the release of IGF-I loaded on the surface of chitosan functionalized GNPs was not hindered and growth factor was desorbed and effectively passed into the cell culture medium inducing a biological effect in cell growth similar to that of free IGF-I [51]. In addition, the released IGF-I maintained a bioactivity equivalent to its released percentage as shown in fig. 8.

Animal Bio-distribution of control and targeted gold nanoparticles

The present study compared the in vivo distribution profiles of $\mathrm{CH}_{3} \mathrm{O}$-PEG-ALK-SH-GNP and IGF-I loaded CS-PEG-ALK-SH-GNP-after $0.25,1,6$ and $24 \mathrm{~h}$ as displayed in fig. 9 and 10. The bio distribution 
profile of each of $\mathrm{CH}_{3} \mathrm{O}$-PEG-ALK-SH-GNP and IGF-I loaded CS-PEGALK-SH-GNP-IGF-I in experimental mice was evaluated based on the GNPs content present in the biological samples collected after IV administration.

For $\mathrm{CH}_{3} \mathrm{O}$-PEG-ALK-SH-GNP, a peak concentration representing about $47 \%$ of the injected nanoparticles was observed in the blood in the first minutes after injection, while, other investigated organs including liver, spleen, and kidneys generally showed very low levels. Fig. 9 shows that after the high peaking of $\mathrm{CH}_{3} \mathrm{O}-\mathrm{PEG}-\mathrm{ALK}-\mathrm{SH}-$ GNP at $0.25 \mathrm{hr}$ in the blood, it started to decrease gradually from the circulation and increase in other tissues with insignificantly higher concentrations reported in the liver $24 \mathrm{hr}$ after injection. These findings may be attributed to the surface PEGylation of GNPs at the time of injection which might have caused the shielding of nanoparticles from being identified and uptaken by organs like the liver and the spleen which are the main organs concerned with the removal of colloids from the body. In addition, the negative charge of those nanoparticles might have contributed to impeding opsonization [54]. This supports that the small percentage of nanoparticles reported up to $6 \mathrm{hr}$ after injection in the liver and spleen are mainly due to the hepatobiliary elimination rather than to the capture of particles by Kupffer cells. Whereas, the significant decrease in $\mathrm{CH}_{3} \mathrm{O}$-PEG-ALK-SH-GNP concentration in the blood and subsequent increase in the liver, spleen, and kidneys after $24 \mathrm{~h}$ might be due to the desorption and removal of PEG moieties away from the GNPs' surfaces followed by opsonization of the non PEGylated GNPs (i.e. unspecific adsorption of negatively charged proteins) [55]. This phenomenon is expected to lead to a large increase in the particles' size resulting in an increased uptake of the large nanoparticles by the reticuloendothelial system especially the liver and spleen [56, 57].

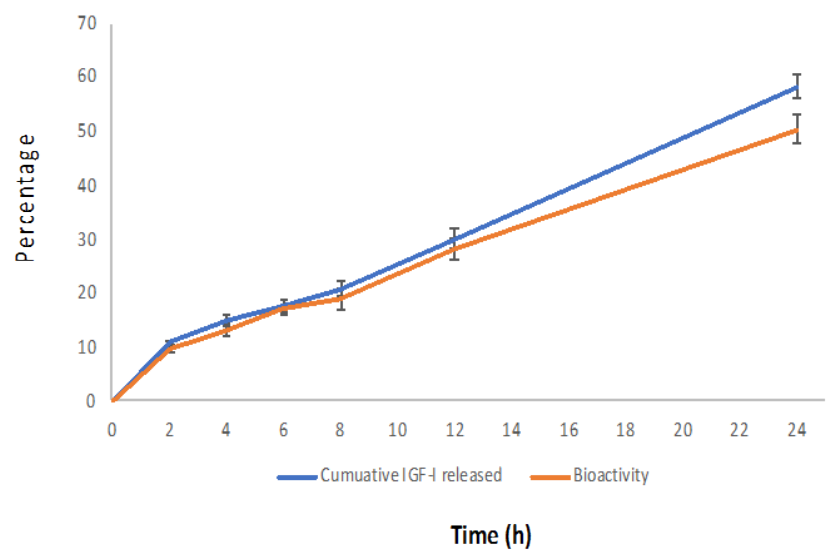

Fig. 8: Shows IGF-I cumulative release along $24 \mathrm{~h}$ and its comparable bioactivity (Results are expressed as mean $\pm S E, n=3$ )

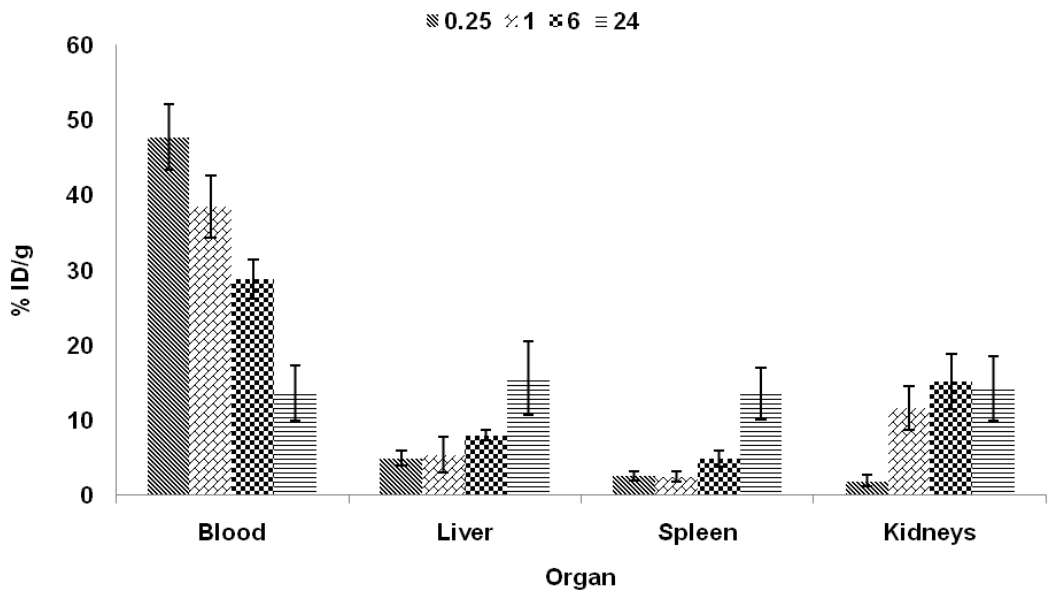

Fig. 9: In vivo distribution of control GNPs ( $\left.\mathrm{CH}_{3} \mathrm{O}-\mathrm{PEG}-\mathrm{ALK}-\mathrm{SH}-\mathrm{GNP}\right)$, (results are expressed as mean $\pm \mathrm{SE}, \mathrm{n}=4$ )

IGF-I loaded CS-PEG-ALK-SH-GNP showed a different in vivo distribution profile as shown in fig. 10. The concentration of IGF-I loaded CS-PEG-ALK-SH-GNP decreased significantly in the blood over time while increasing in the kidneys reaching maximum concentration of about $60 \%$ in $6 \mathrm{~h}$ time. Compared to $\mathrm{CH}_{3} \mathrm{O}-\mathrm{PEG}$ ALK-SH-GNP, the concentration of IGF-I loaded CS-PEG-ALK-SH-GNP in the kidneys were higher at all-time intervals (fig. 10). The maximum concentration of IGF-I loaded CS-PEG-ALK-SH-GNP detected after $6 \mathrm{~h}$ in the kidney was found to be $60 \%$ vs $15 \%$ for $\mathrm{CH}_{3} \mathrm{O}$-PEG-ALK-SH-GNP, $(* \mathrm{P}$ value $=0.039215)$ and it decreased to about $40 \%$ vs $15 \%$, respectively ( $\mathrm{p} \leq 0.05$ ), after $24 \mathrm{~h}$ (fig. 10). The $20 \%$ reduction in IGF-I loaded CS-PEG-ALK-SH-GNP level in the kidney between 6 and $24 \mathrm{~h}$ might be due to the renal clearance process [55]. The level of IGF-I loaded CS-PEG-ALK-SH-GNP in blood decreased gradually from $44.02 \%$ at $0.25 \mathrm{~h}$ after injection to $3.71 \pm 1.12 \%$ at $24 \mathrm{~h}$ time. The high concentration of IGF-I loaded CSPEG-ALK-SH-GNP in kidneys relative to other organs after $6 \mathrm{~h}$ indicates that that the nanoparticles are mainly retained in the kidney which could be attributed to the presence of low molecular weight chitosan, as a specific renal targeting ligand, on the surface of GNPs.

The maximum detected the concentration of $\mathrm{CH}_{3} \mathrm{O}-\mathrm{PEG}-\mathrm{ALK}-\mathrm{SH}-$ GNP in the kidneys was about $15 \%$ after $6 \mathrm{~h}$ and remained nearly constant during the full period of investigation ( $24 \mathrm{~h}$ ) as shown in fig. 10. These results could be a good proof of the excellent renal targeting properties of IGF-I loaded CS-PEG-ALK-SH-GNP-IGF-I [60].

Studies on functionalized GNPs bio distribution have shown that these NPs exhibited longer circulation time in rats [59] and mice 
[60] however, liver and spleen remained their preferential organs, whereas, other studies demonstrated that functionalization through the addition of ligands on the surface of PEG-coated GNPs could be employed as a targeting strategy to guide the NPs to a desired organ as capping confer some stealth capacity that leads to simultaneous reduction in their retention in the spleen and liver [61] which could clearly tailor the in vivo kinetics and biodistribution of GNPs.

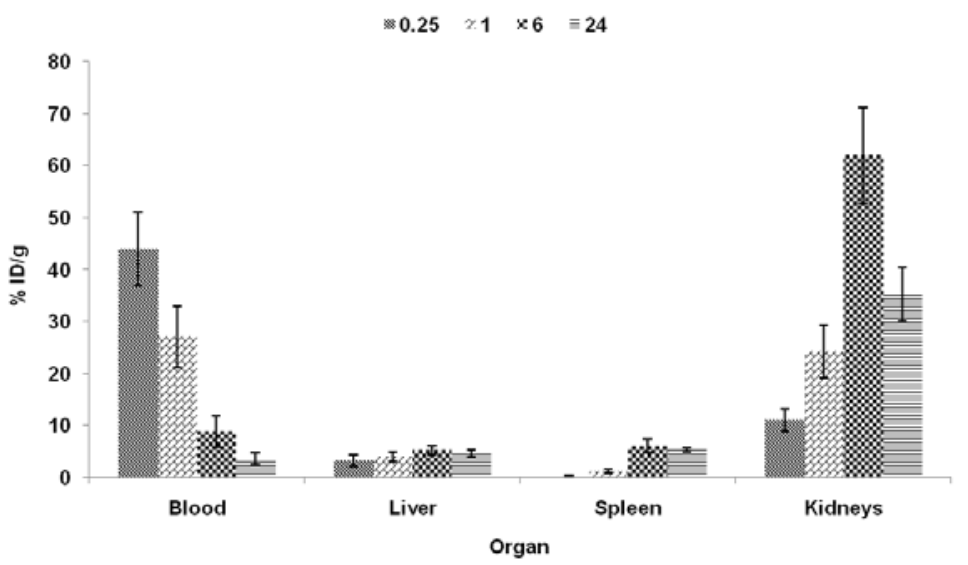

Fig. 10: In vivo distribution of IGF-I loaded CS-PEG-ALK-SH-GNP (Results are expressed as mean \pm SE, $n=4$ )

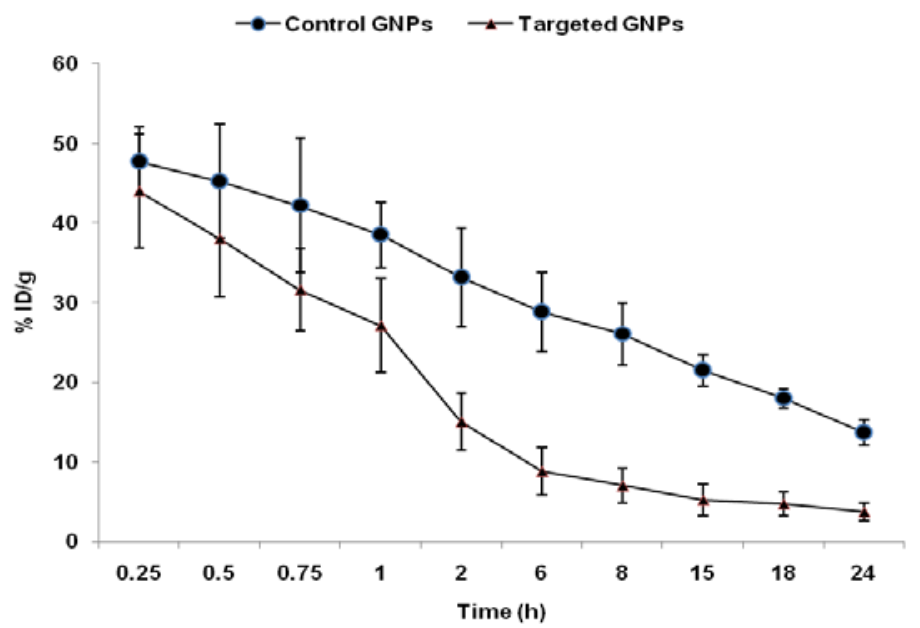

Fig. 11: Blood concentrations of $\mathrm{CH}_{3}$ O-PEG-ALK-SH-GNP and IGF-I loaded CS-PEG-ALK-SH-GNP at different time intervals (results are expressed as mean $\pm S E, n=4$ )

\section{Pharmacokinetic investigation of control and targeting gold nanoparticles}

The calculated pharmacokinetic parameters of both injected $\mathrm{CH}_{3} \mathrm{O}$ PEG-ALK-SH-GNP and IGF-I loaded CS-PEG-ALK-SH-GNP are shown in table 2. The blood concentrations of both $\mathrm{CH}_{3} \mathrm{O}$-PEG-ALK-SH-GNP and IGF-I loaded CS-PEG-ALK-SH-GNP were examined over $24 \mathrm{~h}$ period after intravenous administration in mice veins. At all tested time points the blood concentration of $\mathrm{CH}_{3} \mathrm{O}$-PEG-ALK-SH-GNP was found higher than the concentration of IGF-I loaded CS-PEG-ALK-SHGNP as indicated in fig. 11. In addition, a large Vd value was reported with IGF-I loaded CS-PEG-ALK-SH-GNP over $\mathrm{CH}_{3} \mathrm{O}$-PEG-ALK-SH-GNP and beyond the normal body fluid volume of mice which entails that IGF-I loaded CS-PEG-ALK-SH-GNP accumulate in organ tissues, in our case, in the kidneys as discussed earlier. $\mathrm{CH}_{3} \mathrm{O}$-PEG-ALK-SH-GNP showed prolonged circulation half-life reduced clearance, and reduced volume of distribution (table 2) which is consistent with the findings with Wang et al., 2015 which reported that GNPs with low tissue targeting abilities, shows the fore mentioned featured parameters [62].

The elimination half-life of IGF-I loaded CS-PEG-ALK-SH-GNP-IGF-I was found higher than that of $\mathrm{CH}_{3} \mathrm{O}$-PEG-ALK-SH-GNP, which is explained by the higher affinity and accumulation of IGF-I loaded CSPEG-ALK-SH-GNP-IGF-I in the kidneys and relatively rapid removal form the blood. In the study conducted by Choi et al., PEGylated GNPs of multiple different compositions manifested extended blood circulation, with a half-life $\left(t_{1 / 2}\right)$ that spanned from 7 to $38 \mathrm{~h}$ [63].

Table 2: Pharmacokinetic parameters of control and targeted gold nanoparticles

\begin{tabular}{lll}
\hline Parameter & Control GNPs & Targeted GNPs \\
\hline Conc. at zero time $(\mathrm{Co})$ & $41.98401 \pm 3.12$ & $27.25208 \pm 2.83$ \\
Elimination rate constant, $\mathrm{Ke}\left(\mathrm{h}^{-1}\right)$ & $0.047808 \pm 0.00$ & $0.09962 \pm 0.01$ \\
Half-life, $\mathrm{t}_{0.5}(\mathrm{~h})$ & $14.49552 \pm 0.23$ & $6.956421 \pm 0.09$ \\
Volume of distribution, $\mathrm{Vd}(\mathrm{ml})$ & $2.381859 \pm 0.10$ & $3.669445 \pm 0.31$ \\
Clearance, $\mathrm{Cl}(\mathrm{ml} / \mathrm{h})$ & $0.113872 \pm 0.04$ & $0.365551 \pm 0.02$ \\
\hline
\end{tabular}

*Results are expressed as mean \pm SD, $n=3$, the liver, and spleen have always been the main reservoir sites for metallic nanoparticles through their removal from the circulation by the reticuloendothelial system (RES). 


\section{Toxicity study}

Macroscopic examination of the isolated liver, kidney and spleen tissues showed no changes in tissue size, color and morphology by any of the tested GNP formulations versus the negative control group (group 1) $24 \mathrm{~h}$ after intravenous administration. Also, no behavioral changes were reported in mice of all tested groups with no significant differences in total body weight and feeding pattern, as compared with control animals (data not shown).

As shown in table 3 , there was no significant difference $(p>0.05)$ in blood haematology and in serum clinical chemistry indexes between the three groups of mice proving that the tested functionalized GNPs were not toxic after intravenous administration in mice [62]. In the study conducted by El-Sayed et al., in 2015, rats injected with pegylated gold nanorods in a dose of $0.9 \mathrm{mg} / \mathrm{kg}$ via intravenous and intramuscular routes showed mild symptoms of toxicity [64].

Table 3: Blood haematology and serum clinical chemistry of all mice groups

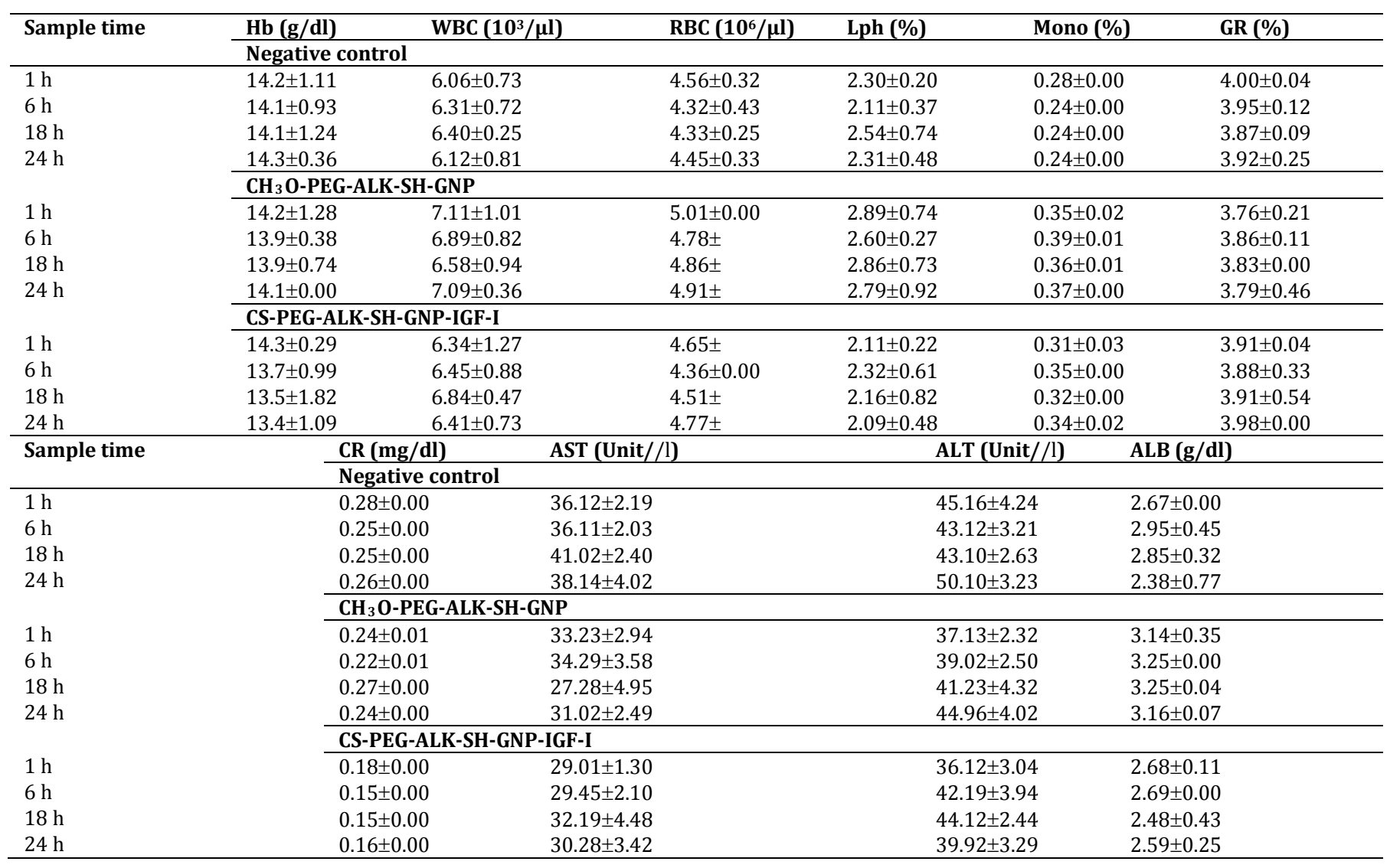

Results are expressed as mean $\pm \mathrm{SD}, \mathrm{n}=3$

\section{CONCLUSION}

Stable GNPs functionalized with chitosan have been successfully prepared and characterized. The surface functionalization of GNPs with chitosan performed dual duties; initially, it acted as a carrier for the growth factor through electrostatic adsorption of negatively charged IGF-I with the positively charged chitosan. Secondly, it acted as a targeting ligand to direct the whole system to be relatively accumulated in the kidney, through an active targeting mechanism. Based on the study results, IGF-I loaded CS-PEG-ALK-SH-GNP represented an efficient tool for the safe, targeted delivery of IGF-I and other biomolecules to the kidneys.

\section{ACKNOWLEDGMENT}

This work was supported financially by the Science and Technology Development Fund (STDF), Egypt.

\section{AUTHORS CONTRIBUTIONS}

All the authors have contributed equally

\section{CONFLICT OF INTERESTS}

There are no conflicts of interest between the presented research work and any other research work.

\section{REFERENCES}

1. Mak RH. Chronic kidney disease in children: state of the art. Pediatr Nephrol 2007;22:1687-8.

2. Liano F, Pascual P. Outcomes in acute renal failure. Semin Nephrol 1998;18:541-50.

3. Mahon P, Shorten G. Perioperative acute renal failure. Curr Opin Anaesthesiol 2006;19:332-8.

4. Lazarus JM, Denker BM, Owen WF. Hemodialysis. In: Brenner BM. editor. The Kidney. Philadelphia: Saunders; 1996. p. 2424506.

5. Jayaraman R, Van der Voort J. Principles of management of chronic kidney disease. Pediatrics Child Health 2010;20:291-6.

6. Molitoris BA, Weinberg JM, Venkatachalam MA, Zager RA, Nath KA, Goligorsky MS. Acute renal failure. II. Experimental models of acute renal failure: imperfect but indispensable. Am J Physiol Renal Physiol 2000;278:F1-F12.

7. Standiford TJ, Huffnagle GB. Cytokines in host defenses against pneumonia. J Investig Med 1997;45:335-45.

8. Toback FG. Regeneration after acute tubular necrosis. Kidney Int 1992;41:226-46.

9. Wagener OE, Lieske JC, Toback FG. Molecular and cell biology of acute renal failure: new therapeutic strategies. New Horizons 1995;3:634-49. 
10. Heldin CH. Dimerization of cell surface receptors in signal transduction. Cell 1995;80:213-23.

11. Nigam SK, Lieberthal W. Acute renal failure III. The role of growth factors in the process of renal regeneration and repair. Am J Physiol Renal Physiol 2000;279:F3-F11.

12. Hammerman MR, Miller SB. Therapeutic use of growth factors in renal failure. J Am Soc Nephrol 1994;5:1-11.

13. Fervenza FC, Tsao T, Rabkin R. Response of the intrarenal insulin-like growth factor axis I to acute ischemic injury and treatment with growth hormone and epidermal factor. Kidney Int 1996;49:344-54.

14. Hammerman MR. Growth factors in renal development. Semin Nephrol 1995;15:291-9.

15. Bier DM. Growth hormone and insulin-like growth factor I: nutritional pathophysiology and therapeutic potential. Acta Paediatr Scand Suppl 1991;374:119-28.

16. Jacob R, Barrett E, Plewe G, Fagin KD, Sherwin RS. J Clin Invest 1989;83:1717-23

17. Hammerman HM. The growth hormone-insulin-like growth factor axis in the kidney. Am J Physiol 1989;257:F503-F514.

18. Kumar P, Roy I. Applications of gold nanoparticles in clinical medicine. Int J Pharm Pharm Sci 2015;8:9-16.

19. Averitt RD, Westcott SL, Halas NJ. Linear optical properties of gold nanoshells. J Opt Soc Am B 1999;16:1824-32.

20. Huang X, Jain PK, El-Sayed IH, El-Sayed MA. Plasmonic photothermal therapy (PPTT) using gold nanoparticles. Laser Med Sci 2008;23:217-28.

21. Tong L, Wei Q, Wei A, Cheng JX. Gold nanorods as contrast agents for biological imaging: optical properties, surface conjugation and photothermal effects. Photo Chem Photo Biol 2009;85:21-32.

22. Shimida A, Kawamura N, Okajima M, Kaewamatawong T, Inoue $\mathrm{H}$, Morita T. Translocation pathway of the intratracheally instilled ultrafine particles from the lung into blood circulation in the mouse. Toxicol Pathol 2006;34:949-57.

23. DeJong WH, Hagens WI, Krystek P, Burger MC, Sips A, Geertsma RE. Particle size-dependent organ distribution of gold nanoparticles after intravenous administration. Biomaterials 2008;29:1912-9.

24. Jain TK, Reddy MK, Morales MA, Leslie-Pelecky DL, Labhasetwar V. Biodistribution, clearance and biocompatibility of iron oxide magnetic nanoparticles in rats. Mol Pharm 2008;5:306-27.

25. Bhadra D, Bhadra S, Jain S, Jain NK. A PEGylated dendritic nanoparticulate carrier of fluorouracil. Int $\mathrm{J}$ Pharm 2003;257:111-24.

26. Wang $M$, Thanou M. Targeting nanoparticles to cancer: review. Pharmacol Res 2010;62:90-9.

27. Paciotti GF, Kingston DGI, Tamarkin L. Colloidal gold nanoparticles: a novel nanoparticle platform for developing multifunctional tumor-targeted drug delivery vectors. Drug Dev Res 2006;67:47-54.

28. Kommareddy S, Amiji M. Poly (ethyleneglycol)-modified thiolated gelatin nanoparticles for glutathione-responsive intracellular DNA delivery. Nanomedicine 2007;3:32-42.

29. Hualin FU, Zhirong Z, Tao G. Influence of the deacetylation degree on the in vivo distribution of chitosan in mice. Latt Am J Pharm 2013;32:1178-83.

30. Zhi-Xiang Y, Jing-Jing L, Di Zhu L, Xun S, Tao G, Zhi-rong Z. Enhanced accumulation of low-molecular-weight chitosan in kidneys: a study on the influence of N-acetylation of chitosan on the renal targeting. J Drug Targeting 2011;19:540-51.

31. Peng Z, Xun S, Zhirong Z. Kidney-targeted drug delivery systems. Acta Pharm Sinica B 2014;4:37-42.

32. Shan G, San H, Frederik DH, Kathrin W, Chuanxu Y, Rikke N, et al. Megalin-mediated specific uptake of chitosan/sirna nanoparticles in mouse kidney proximal tubule epithelial cells enables aqp1 gene silencing. Theranostics 2014;4:1039-51.

33. Xia Kai H, Zhi Xiang Y, Xiao Juan W, Chao Qun X, Wan Yu L. Low molecular weight hydroxyethyl chitosan-prednisolone conjugate for renal targeting therapy: synthesis, characterization and in vivo studies. Theranostics 2012;2:1054-63.

34. Zayed GMS, Tessmar JKV. Heterobifunctional poly(ethylene glycol) derivatives for the surface modification of gold nanoparticles toward bone mineral targeting. Macromol Biosci 2012;12:1124-36.
35. Gadogbe M, Ansar SM, He G, Collier WE, Rodriguez J, Liu D, et al. Determination of colloidal gold nanoparticle surface areas, concentrations, and sizes through quantitative ligand adsorption. Anal Bioanal Chem 2013;405:413-22.

36. Yoo S, Lee J, Young S, Kim Y, Chang P, Gyu H. Effects of selective oxidation of chitosan on physical and biological properties. Int J Biol Macromol 2005;35:27-31.

37. Charhouf I, Bennamara A, Abourriche A, Chenite A, Zhu J, Berrada M. Characterization of dialdehyde chitosan generated by periodate oxidation. Int J Sci Basic Appl Res 2014;4531:336-48.

38. Bordenave N. Advances on selective C- 6 oxidation of chitosan by TEMPO. Biomacromolecules 2008;244:2377-82.

39. Zhu C, Zheng Q, Wang L, Xu HF, Tong J, Zhang Q. Synthesis of novel galactose functionalized gold nanoparticles and its radiosensitizing mechanism. J Nanobiotechnol 2015;13:67-77.

40. Piella J, Bastus NG, Puntes V. Size-controlled synthesis of sub$10 \mathrm{~nm}$ citrate-stabilized gold nanoparticles and related optical properties. Chem Mater 2016;28:1066-75.

41. Khaled AK, Amin MA, Abdelhafez WA, Zayed G, Shaykhon M, Mohamed MS. Synthesis and characterization of gold nanoparticles loaded with 5-fluorouracil. Int J Pharm Pharm Res 2016;6:411-22.

42. Tawfeek HM. Novel gold nanoparticles coated with somatostatin as a potential delivery system for targeting somatostatin receptors. Drug Dev Ind Pharm 2016;42:1782-91.

43. Mahou R, Wandrey C. Versatile route to synthesize heterobifunctional poly (ethylene glycol) of variable functionality for subsequent pegylation. Polymers (Basel) 2012;4:561-89.

44. Madhusudhan A, Reddy GB, Venkatesham M. Efficient $\mathrm{pH}$ dependent drug delivery to target cancer cells by gold nanoparticles capped with carboxymethyl chitosan. Int J Mol Sci 2014;15:8216-34.

45. Bhumkar DR, Joshi HM, Sastry M, Pokharkar VB. Chitosan reduced gold nanoparticles as novel carriers for transmucosal delivery of insulin. Pharm Res 2007;24:1415-26.

46. Elasser M, Abdel-Aziz M, El-Kassas R. Antioxidant, antimicrobial, antiviral and antitumor activities of pyranone derivative obtained from Aspergillus candidus. J Microbiol Biotech Res 2011;1:5-17.

47. Jo M, Bae S, Go M, Kim H, Hwang Y, Choi S. Toxicity and biokinetics of colloidal gold nanoparticles. Nanomaterials 2015;5:835-50.

48. Mohamed AI, Hussain AK, Zayed GM, Shaykoon M, Mahmoud RA. Preparation and characterization of cytotoxic drug-loaded gold nanoparticles. Int J Pharm Pharm Res 2016;6:640-52.

49. Kumar D, Meenan BJ, Mutreja I, D'SA R, Dixon D. Controlling the size and size distribution of gold nanoparticles: a design of experiment study. Int J Nanosci 2012;11:1-7.

50. Sebak AA. Particle size enlargement has been observed on comparison of PEGylated and non-PEGylated nanocarriers. Int J Appl Pharm 2018;10:6-12.

51. Shalkevich N, Shalkevich A, Si-ahmed L, Bu T. Reversible formation of gold nanoparticle-surfactant composite assemblies for the preparation of concentrated colloidal solutions. Phys Chem Chem Phys 2009;11:10175-9.

52. Mukohara T, Shimada H, Ogasawara N, Wanikawa $R$, Shimomura M, Nakatsura T, et al. Sensitivity of breast cancer cell lines to the novel insulin-like growth factor-1 receptor (IGF-1R) inhibitor NVP-AEW541 is dependent on the level of IRS-1 expression. Cancer Lett 2009;282:14-24.

53. De Blaquiere GE, May FE, Westley BR. Increased expression of both insulin receptor substrates 1 and 2 confers increased sens itivity to IGF-1 stimulated cell migration. Endocr Relat Cancer 2009;16:635-47.

54. Faure AC, Dufort S, Josserand V, Perriat P, Coll JL, Roux S, Tillement 0 . Control of the in vivo biodistribution of hybrid nanoparticles with different poly(ethylene glycol) coatings. Small 2009;5:2565-75.

55. Alric C, Miladi I, Kryza D, Taleb J, Lux F, Bazzi R, et al. The biodistribution of gold nanoparticles designed for renal clearance. Nanoscale 2013;5:5930-9.

56. Varna M, Ratajczak P, Ferreira I, Leboeuf C, Bousquet G, Janin A. In vivo distribution of inorganic nanoparticles in preclinical models. J Biomater Nanobiotechnol 2012;3:269-79. 
57. Alalaiwe A, Roberts G, Carpinone P, Munson J. Influence of PEG coating on the oral bioavailability of gold nanoparticles in rats Influence of PEG coating on the oral bioavailability of gold nanoparticles in rats. Drug Delivery 2017;24:591-8.

58. He X, Yuan $\mathrm{Z}, \mathrm{Wu} \mathrm{X}, \mathrm{Xu} \mathrm{C}$, Li W. Low molecular weight hydroxyethyl chitosan-prednisolone conjugate for renal targeting therapy: synthesis, characterization and in vivo studies. Theranostics 2012;2:1054-63.

59. Lipka J, Semmler Behnke M, Sperling RA, Wenk A, Takenaka S, Schleh $\mathrm{C}$, et al. Biodistribution of PEG-modified gold nanoparticles following intratracheal instillation and intravenous injection. Biomaterials 2010;31:6574-81.

60. Cho WS, Cho M, Jeong J, Choi M, Han BS, Shin HS, et al. Sizedependent tissue kinetics of PEG-coated gold nanoparticles. Toxicol Appl Pharmacol 2010;245:116-23.
61. Guerrero S, Herance JR, Rojas S, Mena JF, Gispert JD, Acosta GA, et al. Synthesis and in vivo evaluation of the biodistribution of a $18 \mathrm{~F}$ labeled conjugate gold-nanoparticle-peptide with potential biomedical application. Bioconjugate Chem 2012;23:399-408.

62. Wang J, Bai R, Yang R, Liu J, Tang J, Liu Y, et al. Size-and surface chemistry-dependent pharmacokinetics and tumor accumulation of engineered gold nanoparticles after intravenous administration. Metallomics 2015;7:516-24.

63. Choi CHJ, Zuckerman JE, Webster P, Davis ME. Targeting kidney mesangium by nanoparticles of defined size. Proc Natl Acad Sci 2011;108:6656-61.

64. El-Sayed MA, Yassin NA, Shabaka AA, El-Shbrawy OA, Mahmoud SS, El-Shenawy SM, et al. Toxicological and pharmacological assessment of gold nanorods in normal rats. Int J Pharm Pharm Sci 2015;7:41-50. 